\section{Original Article}

Dr. Ashis Kumar Biswas BDS, MCPS, FCPS Orthodontics and

Dentofacial Orthopedics

Dr. Gazi Shamim Hassan BDS, PhD, FWFO

Chairman \& Associate Professor Dept. of Orthodontics Bangabandhu Sheikh Mujib Medical University

Dr. Nasreen Akhter BDS, FCPS Medical Officer Dept. of Orthodontics Bangabandhu Sheikh Mujib Medical University

Dr. Ranjit Ghosh BDS, MCPS, FCPS Orthodontics and Dentofacial Orthopedics

Dr. Mohammad Rakibul Islam Babu BDS, FCPS

Orthodontics and Dentofacial Orthopedics

\title{
A Study on Arch Length Among Dentoalveolar Class I, Class II and Class III Malocclusion of Bangladeshi Population
}

\section{Abstract :}

Objectives : To study the variations in arch length among different classes of dento-alveolar malocclusion in the permanent dentition. Materials and Methods: Both male and female Bangladeshi subjects with permanent dentition who attended during 1st July 2007 to 1st January 2011 to the Department of Orthodontics , BSMMU for treatment were included in this study. Dental arch length were measured from dental casts of the permanent dentition of 96 Bangladeshi subjects of which 48 male, 48 female, 24 class 1, 24 class 2 div. I, 24 class 2 div. II, 24 class III. Arch length was measured by adapting a length of brass wire (diameter $0.5 \mathrm{~mm}$ ) on the maxillary and mandibular arches. Comparison of arch length was done among different malocclusion classes.

Results: In these study we found maxillary arch length was largest in class II div. 1 malocclusion. Mandibular arch length was highest in class III and lowest in class II div. 1 malocclusion. Least significant difference (LSD) is used to compare two of the four group . $\mathrm{P}<0.05$ was set as the level of significance.

Conclusions : Class III malocclusion has large lower arch and short upper arch. In Class II division 1, arch length is larger in upper than lower arch and Class II division 2 show the shortest maxillary arch length.

Key words : Dental arch, arch length, malocclusion.

\section{Introduction :}

Arch length is one which denotes the basal perimeter on the skeletal bases, where teeth should be placed in normal alignment.[1] The dimension of dental arches was measured by estimation of inter-canine width, inter-molar width and arch length of maxillary and mandibular arches [2] and it could be affected by many factors such as heredity, growth of the bone, eruption \& inclination of the teeth, racial background and environmental factors such as muscle forces and function $[3,4,5]$.

Dental arch forms have considerable implications in orthodontic diagnosis and treatment planning, as it affects the space available, dental aesthetics, and stability of the dentition. These considerations, in association with the antero-posterior movements of the dentition, will determine the requirements for extraction or non extraction treatment [6].

Without information about the arch length of different type malocclusion, it is difficult for a clinician to make a proper diagnosis and treatment plan .The literature review indicates that many investigators found differences in dental arch length in different types of malocclusion, as a result, a comparative study was required to standardized the arch length of Bangladeshi population.

\section{Objectives:}

General Objective:

To study dental arch lengh of different classes of dento-alveolar malocclusion of permanent dentition. 


\section{Specific Objectives:}

To compare the dental arch length on the dental cast among dento-alveolar Class-I, Class-II and Class-III malocclusion groups.

\section{Materials and Methods :}

At first 96 study model (48 of male, 48 of female, 24 of class-1, 24 of class-2 div. I, 24 of class-2 div. II, 24 class-III malocclusion) was collected from the archive of orthodontic department of BSMMU according to selection criteria (inclusion and exclusion criteria). Then data of this study is measured with $0.5 \mathrm{~mm}$ brass wire and recorded in the data collection sheet.

\section{Selection criteria:}

Inclusion criteria:

a) Permanent dentition

b) Normal anatomy of teeth

Exclusion criteria:

a) Primary or mixed dentition

b) Grossly carious teeth

c) Missing teeth

d) Supernumerary teeth

e) Asymmetric arch form

f) Rotation of molar and canine teeth

g) Molar and canine teeth out of arch line

\section{Data collection procedure:}

Arch length is measure by

${ }^{* *}$ The maxillary arch length was measured as the distance from mesial marginal ridge of maxillary first permanent molar passing through the central fissures of first and second premolars and the cingulam of the canine to the midline passing through the cingulum of the lateral and central incisors. This was repeated on the other side. These values were then summed up to determine the maxillary dental arch length [2]

** The mandibular arch length was measured as the distance from mesial marginal ridge of the first mandibular molar passing through the buccal cusp tips of the premolars and tip of the canine to the lingual surface of the lateral incisors and from there to the midline passing through the incisal edges of the lateral and central incisors. This was repeated on the other side. These values were then summed up to determine the mandibular dental arch length [2]

\section{Data analysis:}

Data of this study are computerized and analyzed using SPSS for window version 10, strata version 10. One -way analysis of the variables (ANOVA) is used to check the statistical significance of the variables among Class-I, Class-II division 1, Class-II division 2, Class-III malocclusions. Least significant difference (LSD) is used to compare two of the four group . $\mathrm{P}<0.05$ is set as the level of significance.

\section{Results :}

Among 96 study model, $50 \%$ of study model are of female patients and $50 \%$ of study model are of male patients (Table-1, Figure- 2).

\begin{tabular}{|c|c|c|c|}
\hline \multicolumn{4}{|c|}{ Table 1: Distribution of subjects according to gender and malocclusion groups } \\
\hline $\begin{array}{c}\text { Malocclusion } \\
\text { group }\end{array}$ & $\begin{array}{c}\text { Number } \\
\text { of males }\end{array}$ & $\begin{array}{c}\text { Number } \\
\text { of } \\
\text { females }\end{array}$ & Total \\
\hline Class-I & 12 & 12 & 24 \\
Class-II & 12 & 12 & 24 \\
division 1 & 12 & 12 & 24 \\
Class-II & 12 & 24 \\
division 2 & & & \\
Class-III & 12 & & \\
Grand total & 48 & & \\
\hline
\end{tabular}

Figure 1: Distribution of groups (class 1, class II division-1, class II division-2 and class III)

Mean and standard deviation (descriptive statistics) of different variables (Mandibular AL and Maxillary AL) compared in this study are given in Table2, Figure 2-8)

\begin{tabular}{|c|c|c|c|c|c|c|c|c|}
\hline \multicolumn{9}{|c|}{ Table 2: Mean arch length in four malocclusion groups } \\
\hline \multirow[t]{2}{*}{ Dental arch length } & \multicolumn{2}{|c|}{ Class-1 } & \multicolumn{2}{|c|}{ Class-Il division 1} & \multicolumn{2}{|c|}{ Class-Il division 2} & \multicolumn{2}{|c|}{ Class-II } \\
\hline & Mean & SD \pm & Mean & SDt & Mean & $S D \pm$ & Mean & $S D \pm$ \\
\hline Mandibular AL & 68.11 & 1.67 & 66.14 & 1.24 & 66.59 & 1.52 & 70.37 & 1.06 \\
\hline Maxillary AL & 72.40 & 0.94 & 72.76 & 1.30 & 70.07 & 1.47 & 69.23 & 0.99 \\
\hline
\end{tabular}

\begin{tabular}{|c|c|c|c|c|c|}
\hline \multicolumn{6}{|c|}{ Table 4: Comparison of maxillary and mandibular arch length among four malocclusion groups (n=96) } \\
\hline length & Class & No of patients & Mean & SD & P.value \\
\hline \multirow[t]{5}{*}{ Mandibular AL } & 1 & 24 & 68.11 & 1.67 & \multirow{5}{*}{$0.0000^{\circ}$} \\
\hline & $\|$ div 1 & 24 & 66.14 & 1.24 & \\
\hline & \|ldiv2 & 24 & 66.59 & 1.52 & \\
\hline & III & 24 & 70.37 & 1.06 & \\
\hline & । & 24 & 72.40 & .94 & \\
\hline \multirow[t]{3}{*}{ Maxillary AL } & $\|$ div 1 & 24 & 72.76 & 1.30 & \multirow[t]{3}{*}{$0.0000^{*}$} \\
\hline & \|l div2 & 24 & 70.07 & 1.47 & \\
\hline & \|\| & 24 & 69.23 & .99 & \\
\hline
\end{tabular}

\begin{tabular}{|c|c|c|c|c|c|c|}
\hline \multicolumn{7}{|c|}{ Table 4: Table 4: Comparison of maxillary and mandibulalar arch length between individual malocclusion groups } \\
\hline Dental Arch & Class-I vs & Class.t vs & Class-I & Class-I div1 vs. & Class-| div1 & Class-I div2 \\
\hline \multirow[t]{2}{*}{ length } & Class-I div & Class-II div2 & vs Class- & Class-Il div2 & vs. Class-ll| & vs. Class-\|ll \\
\hline & $\begin{array}{c}1 / p . \\
\text { valué Class }\end{array}$ & (P.value) & $\begin{array}{l}\| 1 \mid \\
\text { va.ue }\end{array}$ & (P.value) & (P. value & (P. value) \\
\hline Mandibular AL & .000 & .000 & .000 & .000 & .268 & 268 \\
\hline Maxilary AL & 304 & .000 & .000 & .000 & .000 & .018 \\
\hline
\end{tabular}




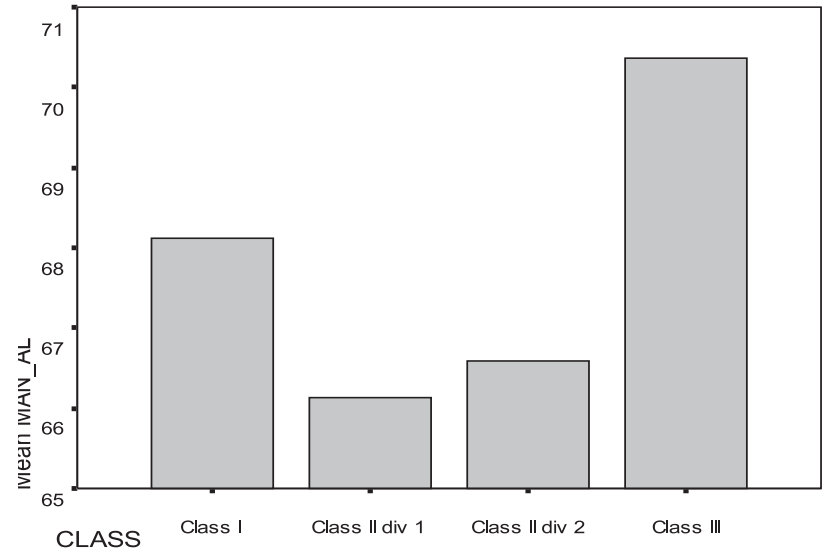

Figure 2: Bar diagram of mean mandibular arch length of four groups of malocclusions.

\section{Mandibular Arch Length :}

The highest mean mandibular arch length was found in Class-III followed by Class I group with the smallest value found in Class II div.1 group. A comparison among the four groups was statistically significant $(P=0.0000)$ as shown in Table3. Significant difference is found except Class II div. 1 and Class III, Class II div. 2 and Class III when individual groups were compared as shown in Table 4. This can be interpreted that patients with class II div.1 malocclusion have short arch length than those with class-I.

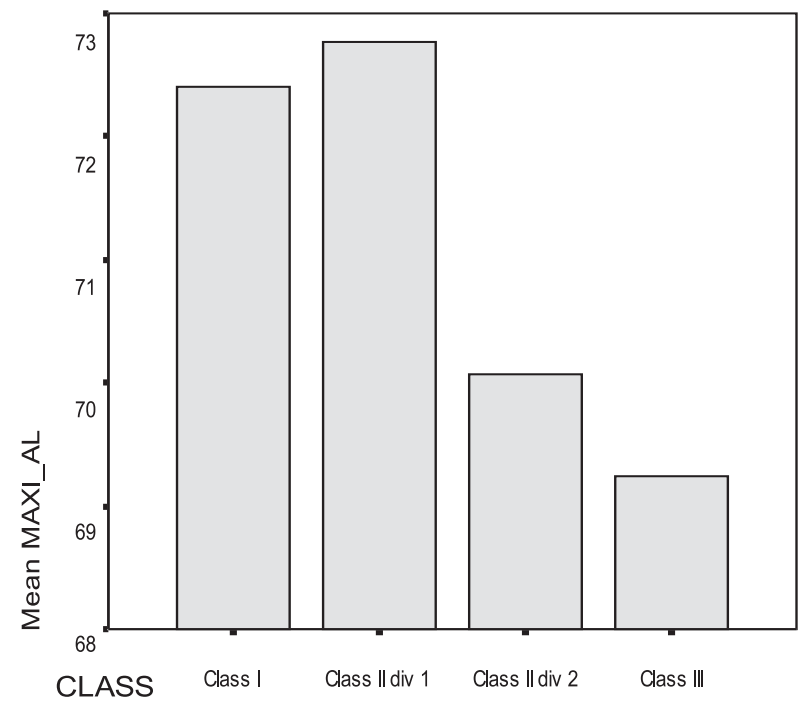

Figure 3: Bar diagram of mean maxillary arch length of four groups of malocclusions.

\section{Maxillary Arch Length :}

The largest arch length was noted for Class II div.1 group followed by class I while the Class III group showed the smallest value of maxillary arch length. However the difference among the four groups was statistically significant $(P=0.0000)$ as shown in Table 3. A comparison between individual groups showed only that Class I and Class II div. 1 were significantly different (Table 4).

\section{Discussion :}

This study was done at the Department of Orthodontics, Faculty of Dentistry, Bangabandhu Sheikh Mujib Medical University from 1st July 2007 to 1st January 2011 with a sample size of 96 patients. At first study model was prepared with stone plaster pouring it into impression of maxillary and mandibular arch . Patients detail is collected from departmental record book. Arch length is measures with adapting $0.5 \mathrm{~mm}$ brass wire. The collected data were then analyzed statistically by using SPSS for window 10 and strata version 10. When a comparison was done in this study among groups of malocclusion it was found that significantdifference ( $p$ value $=0.0000$ ) was present in mandibular arch length and The largest mean value was found in class III malocclusion. This was a similar result, found in the study by some other investigator as $[2,7]$

In this comparative study on maxillary arch length, we found significant difference ( $p$ value $=0.0000$ ) between among the four groups of malocclusion. The largest maxillary arch length in this study, was found in class- II division 1 malocclusion. This also similar result found in the investigation done by another auther [7]

\section{Conclusion :}

In the study, the dental arch length of permanent dentition in dento-alveolar class I, class II division1, class II division 2 and class III malocclusion was measured and compared. From the result, it may be concluded and suggested that,

1. Largest mandibular arch length is found in class III malocclusion due to mandibular prognathism. Smallest mandibular arch length is associated with class II division 1 and causes large overbite

2. Class II division1 has maximum maxillary arch length and so gives a common compliant of proclination. Class III malocclusion show minimum maxillary arch length and characterized by midface hypoplasia

\section{References :}

1. Kharbanda OP. Diagnosis and Management of Malocclusion and dentofacial Dentofacial deformity (1st edition). Mosby Elsevier,2009: p 129.

2. Rosool G, Kundi I. Comparison of dental arch dimensions among various malocclusion classes. J. Med. Sci.(Peshawar print) july 2009, vol.17,No.2: 71-77

3. Lavelle CL, Foster TD, Flinn RM. Dental arches in various ethnic groups. Angle Orthod 1971; 41: 293-99.

4. Bjork A, Brown T, Skieller V. Comparison of craniofacial growth in Australian Aboriginal and Danes, illustrated by longitudinal cephalometric analysis. Eur J Orthod 1984; 6: 1-14.

5. Hassanali J, Odhiambo W. Analysis of dental casts of 6-8 and 12-year old Kenyan children. Eur J Orthod 2000; 22: 135-142.

6. Lee RT. Arch width and form: a review. Am J Orthod. 1999; 115:305-13.

7. Al-Khateeb SN, Abu-Alhaija ESJ. Tooth size discrepancies and arch parameters among different malocclusions in a Jordanian sample. Angle Orthod 2006; 76: 459-65. 